\title{
Regional differences in where and how family medicine residents intend to practise: a cross-sectional survey analysis
}

\author{
M. Ruth Lavergne PhD, Ian Scott MSc MD, Goldis Mitra MD, David Snadden MBChB MD, \\ Doug Blackie MPA, Laurie J. Goldsmith PhD, David Rudoler PhD, Lindsay Hedden PhD, \\ Agnes Grudniewicz PhD, Megan A. Ahuja MPH, Emily Gard Marshall PhD
}

\section{Abstract}

Background: Family medicine residents choose among a range of practice options as they enter the physician workforce. We describe the demographic and personal characteristics of Canadian family medicine residents and examine differences in the intentions of residents from Ontario, Quebec, Western Canada and Atlantic Canada at the completion of their training, in terms of practice comprehensiveness, organizational model, clinical domains, practice settings and populations served.

Methods: We analyzed national survey data collected by the College of Family Physicians of Canada and 16 university-based family medicine residency programs. We tabulated bivariable descriptive results and used logistic regression to estimate odds of practice intentions across regions, adjusting for family medicine resident characteristics.

Results: Of 1680 respondents (61.5\% of 2731 family medicine residents invited to participate), $66.3 \%(n=1095)$ reported it was somewhat or highly likely they would commit to providing comprehensive care to the same group of patients within their first 3 years of practice. This percentage varied from $40.3 \%$ in Atlantic Canada to $85.1 \%$ in Ontario. In addition, $31.5 \%$ ( $n=522$ ) reported it was somewhat or highly likely they would focus only on specific clinical areas. Most respondents reported it was somewhat or highly likely that they would practise in a group physician practice $(93.8 \%)$ or interprofessional team-based practice $(88.1 \%)$, and only $7.7 \%$ expected to have a solo practice.

Interpretation: Intentions for comprehensive and focused practice varied, but over $80 \%$ of family medicine residents indicated they intended to practise in a team-based model in all regions. Policy-makers and workforce planners should consider the impact of family medicine residents' intentions on policy objectives.

hallenges in accessing primary care persist across Canada despite historically high ratios of primary care providers per capita. ${ }^{1-4}$ Changes in the amounts primary care physicians work ${ }^{5}$ and in the types of services they deliver ${ }^{6,7}$ may help explain this. Upon completion of training, family physicians may choose comprehensive (generalist) practice or may focus their practice on a particular clinical area (e.g., emergency medicine, palliative care, sports medicine or addictions medicine). They may also choose among several organizational models, including solo practice, group physician practice and interprofessional team-based care, as well as clinical domains, populations served and practice settings. Their choices may shape the supply of primary care services available to patients. Organizational models and associated payment systems (e.g., fee-for-service, salary, capitation) vary markedly among regions in Canada ${ }^{8-10}$ and may also shape physician practice choices and behaviour. ${ }^{11-14}$

Although some research has examined medical students' choice of family medicine as a specialty, ${ }^{15-18}$ there is only limited information available about the practice intentions of Canadian family medicine residents. ${ }^{19,20}$ In the present study, we answer the following question: Do the practice intentions of family medicine residents differ among regions in Canada? We use national survey data to describe demographic and personal characteristics of family medicine residents and examine differences in the intentions of residents from Ontario, Quebec, Western Canada and Atlantic Canada with respect to practice comprehensiveness, organizational model, clinical domains, practice settings and populations served.

\section{Competing interests: None declared.}

This article has been peer reviewed.

Correspondence to: Ruth Lavergne, ruth_lavergne@sfu.ca CMAJ Open 2019. DOI:10.9778/cmajo.20180152 


\section{Methods}

\section{Data}

We analyzed data from the Family Medicine Longitudinal Survey, which was administered by the College of Family Physicians of Canada to trainees in 16 university-based family medicine residency programs. ${ }^{21}$ The Family Medicine Longitudinal Survey was developed by the College of Family Physicians of Canada as part of a program evaluation of curricular reforms within family medicine residency (the Triple C competency-based curriculum). ${ }^{21}$ The survey was piloted in 2012 and 2013 in 8 family medicine programs. Questions were developed to reflect graduates' intentions for practice and confidence in their skills and knowledge upon completion of their residency program. ${ }^{22}$ The survey also provides information about graduate experience with the curriculum, but this is outside the scope of our analysis.

Surveys were sent to all family medicine residents in Canada within 3 months of program completion and were offered both in paper format and online. ${ }^{22}$ Our analysis focused on responses to questions about practice intentions with respect to comprehensiveness, organizational model, clinical domains, settings and populations served (see full questions in Appendix 1 available at www.cmajopen.ca/content/7/1/E124/suppl/DC1) among family medicine residents exiting residency in 2016 and 2017. The survey measured intentions for practice on a 5 -point Likert scale: "highly likely," "somewhat likely," "neutral," "somewhat unlikely" or "highly unlikely."

\section{Analysis}

We dichotomized responses by grouping the "somewhat likely" and "highly likely" responses and the "neutral," "somewhat unlikely" and "highly unlikely" responses. Responses were not normally distributed and we could not assume they could be treated as interval data. Given the number of practice intention variables analyzed it was also impractical to report frequencies across all 5 categories for each scale. Dichotomizing responses in this way provides interpretable results where proportions and odds reflect positive intentions for each practice variable. We conducted sensitivity analysis to confirm that grouping the "neutral" responses with the "somewhat likely" and "highly likely" responses resulted in similar patterns across regions.

We summarized the demographic and personal characteristics of respondents and the number and percentage of respondents selecting "somewhat likely" or "highly likely" for all survey questions capturing practice intentions, overall and in each region (Atlantic Canada, Quebec, Ontario and Western Canada; data were provided only by region). We investigated differences among regions using $\chi^{2}$ tests. To explore how survey respondents differ from all family medicine residents we compared respondent characteristics with publicly available data from the Canadian Post-MD Education Registry. ${ }^{23}$

We used logistic regression to examine the relationship between region and each dichotomized practice intention variable. Multivariable models controlled for sex/gender, location of medical training (Canadian or international medical graduates), age and childhood geographic environment (inner city/urban/ suburban, small town, rural/remote/isolated or mixed [if the respondent lived in more than 1 type of environment]). (Note that the survey used the word sex, but we use the term sex/gender because it was not possible in this analysis to distinguish between sex and gender effects: it is plausible that biological differences specific to pregnancy and childbirth may shape intentions to some degree, but it is likely that socially constructed gender plays a larger role.) We excluded the number of years in service because it was colinear with age. We also included a control variable that captured whether family medicine residents intended to work in an urban or rural environment. We did this because intentions for specific clinical domains, settings and populations may be closely connected to whether family medicine residents anticipated practising in a rural or urban environment and intentions for rural practice differed markedly among regions. We confirmed that patterns across regions were similar in models including years of service instead of age and excluding intentions for work in an urban or rural environment. Respondents for whom data were missing for variables other than the outcome of interest were retained with indicator variables for "missing/prefer not to answer." We excluded respondents with missing data for practice outcomes from each model. In describing results of logistic regression, we report odds of intentions for each practice outcome, as shorthand for odds of selecting "somewhat likely" or "highly likely" versus selecting "neutral," "somewhat unlikely" or "highly unlikely."

\section{Ethics approval}

Ethics approval was obtained from each participating residency program's local ethics boards to implement the survey as part of a longitudinal study and program evaluation plan. ${ }^{21}$ Ethics approval for secondary analysis of the Family Medicine Longitudinal Survey data was obtained from the Simon Fraser University Research Ethics Board (reference no. 2017s0157).

\section{Resullts}

\section{Characteristics of respondents}

All 2731 family medicine residents exiting residency in Canada in 2016 and 2017 were invited to complete the survey. Response rates were 60.1\% (785/1306) in 2016 and $62.8 \%$ $(895 / 1425)$ in 2017 ; the overall response rate was $61.5 \%$. We observed statistically significant differences among regions with respect to sex/gender, training location, age, number of years since medical degree was obtained and childhood environment (Table 1). A total of $62.4 \%$ of respondents were women $(n=1027)$; the percentage varied from $54.7 \%(n=$ $355)$ in Western Canada to $68.1 \%(n=378)$ in Ontario. The percentage of international medical graduates varied from $4.8 \%(n=24)$ in Ontario to $21.1 \%(n=140)$ in Western Canada. Ontario respondents were younger and had more recently completed their MDs than respondents from the other regions of the country. Quebec had the highest percentage of respondents reporting that they grew up in an inner city, urban or suburban environment $(71.7 \%, n=276)$ and Atlantic Canada the lowest $(47.6 \%, n=30)$. 
We compared 2017 survey respondents with all family medicine residents in the Canadian Post-MD Education Registry $^{22}$ in 2017. Among the 895 respondents exiting residency in 2017 , the average age was 30.5 years, $546(61.0 \%)$ were women and $131(14.6 \%)$ were international medical graduates. The percentages were comparable for the 1438 family medicine trainees exiting residency in 2017 captured in the Canadian Post-MD Education Registry ${ }^{22}$ : the average age was 30.1 years, $62.1 \%$ were women and $15.5 \%$ were international medical graduates.

Responses to questions about practice intentions were missing for between $19(1.0 \%$, questions $16 \mathrm{~b}$ and $16 \mathrm{c})$ and 104 respondents $(6.2 \%$, question $21 \mathrm{n})$. The number of respondents included in the analysis of each practice intention variable is reported in Table 2.

\section{Comprehensive care and confidence in current ability}

Across Canada, $66.3 \%$ of family medicine residents $(n=1095)$ reported it was somewhat or highly likely they would commit to providing comprehensive care to the same group of patients in their first 3 years of practice. This varied from $40.3 \%(n=27)$ in Atlantic Canada to $85.1 \%(n=474)$ in Ontario (Table 2). Over $90 \%$ of respondents $(n=1529)$ reported they were confident in their ability to provide comprehensive care to the same group of patients over time; the percentage was slightly lower in Atlantic Canada $(82.1 \%, n=$ 55). In multivariable models, significant differences in intentions to provide comprehensive care persisted, but regional differences in confidence were not significant (Appendix 2 available at www.cmajopen.ca/content/7/1/E124/suppl/DC1).

\section{Organizational models}

Higher percentages of respondents in Quebec $(65.7 \%, n=251)$ and Western Canada $(63.7 \%, n=416)$ than in the other regions indicated that they intended to provide care in 1 clinical setting (Table 2). This effect persisted in multivariable analysis (Appendix 2). A higher percentage of respondents in Atlantic Canada than in the other regions anticipated providing care across multiple clinical settings $(83.6 \%, n=56)$ (Table 2). This effect was attenuated in multivariable analysis (Appendix 2).

\begin{tabular}{|c|c|c|c|c|c|c|}
\hline \multirow[b]{2}{*}{ Characteristic } & \multicolumn{5}{|c|}{ No. (\%) of respondents } & \multirow[b]{2}{*}{$p$ value* } \\
\hline & $\begin{array}{c}\text { Total } \\
n=1680\end{array}$ & $\begin{array}{l}\text { Ontario } \\
n=561\end{array}$ & $\begin{array}{l}\text { Western } \\
\text { Canada } \\
n=663\end{array}$ & $\begin{array}{c}\text { Atlantic } \\
\text { Canada } \\
n=68\end{array}$ & $\begin{array}{l}\text { Quebec } \\
n=388\end{array}$ & \\
\hline Sex/gender & & & & & & $<0.001$ \\
\hline Male & $619(37.6)$ & $177(31.9)$ & $291(45.3)$ & $23(35.4)$ & $128(33.7)$ & \\
\hline Female & $1027(62.4)$ & $378(68.1)$ & $355(54.7)$ & $42(64.6)$ & $252(66.3)$ & \\
\hline Location of MD training & & & & & & $<0.001$ \\
\hline Canada & $1386(85.6)$ & $477(95.2)$ & $523(78.9)$ & $59(86.8)$ & $327(84.5)$ & \\
\hline International & $233(14.4)$ & $24(4.8)$ & $140(21.1)$ & $9(13.2)$ & $60(15.5)$ & \\
\hline Age, yr & & & & & & $<0.001$ \\
\hline$<30$ & $931(58.6)$ & $410(73.3)$ & $318(48.3)$ & $28(42.4)$ & $175(57.0)$ & \\
\hline $30-34$ & $433(27.2)$ & $80(14.3)$ & $222(33.7)$ & $24(36.4)$ & $107(34.9)$ & \\
\hline$\geq 35$ & $226(14.2)$ & $69(12.3)$ & $118(17.9)$ & $14(21.2)$ & $25(8.1)$ & \\
\hline $\begin{array}{l}\text { Time since completion } \\
\text { of MD training, } y r\end{array}$ & & & & & & $<0.001$ \\
\hline 2 & $1325(79.1)$ & $470(83.8)$ & $489(74.0)$ & $56(82.4)$ & $310(80.3)$ & \\
\hline 3 & $145(8.7)$ & $28(5.0)$ & $67(10.1)$ & $8(11.8)$ & $42(10.9)$ & \\
\hline$\geq 4$ & 206 (12.3) & $63(11.2)$ & $105(15.9)$ & $4(5.9)$ & $34(8.8)$ & \\
\hline Childhood environment & & & & & & $<0.001$ \\
\hline $\begin{array}{l}\text { Inner city, urban or } \\
\text { suburban }\end{array}$ & $1051(63.0)$ & $317(56.5)$ & $428(64.9)$ & $30(47.6)$ & $276(71.7)$ & \\
\hline Small town & $280(16.8)$ & $107(19.1)$ & $93(14.1)$ & $15(23.8)$ & 65 (16.9) & \\
\hline Rural, remote or isolated & $234(14.0)$ & $92(16.4)$ & $96(14.6)$ & $15(23.8)$ & $31(8.1)$ & \\
\hline Mixed & $103(6.2)$ & $45(8.0)$ & $42(6.4)$ & $3(4.8)$ & $13(3.4)$ & \\
\hline
\end{tabular}


Table 2: Practice intentions of family medicine residents exiting residencies in 2016 and 2017 who responded to the Family Medicine Longitudinal Survey, by region

\begin{tabular}{|c|c|c|c|c|c|c|}
\hline \multirow[b]{2}{*}{ Intention } & \multicolumn{5}{|c|}{ No. $(\%)$ of respondents } & \multirow[b]{2}{*}{$p$ value* } \\
\hline & Total & Ontario & $\begin{array}{l}\text { Western } \\
\text { Canada }\end{array}$ & $\begin{array}{l}\text { Atlantic } \\
\text { Canada }\end{array}$ & Quebec & \\
\hline \multicolumn{7}{|l|}{ Comprehensive care and confidence in current ability } \\
\hline $\begin{array}{l}\text { Residents reporting that it was somewhat or highly likely that } \\
\text { they would commit to providing comprehensive care to the } \\
\text { same group of patients in their first } 3 \text { years of practice } \\
\text { (Q17, } n=1652 \text { ) }\end{array}$ & $1095(66.3)$ & $474(85.1)$ & $401(61.2)$ & $27(40.3)$ & $193(51.7)$ & $<0.001$ \\
\hline $\begin{array}{l}\text { Residents reporting that they agreed or strongly agreed with } \\
\text { this statement: "I am confident in my current ability to provide } \\
\text { comprehensive care to the same group of patients over time." } \\
\text { (Q19, } n=1658 \text { ) }\end{array}$ & $1529(92.2)$ & $509(91.2)$ & $609(93.4)$ & $55(82.1)$ & $356(93.4)$ & 0.006 \\
\hline \multicolumn{7}{|l|}{$\begin{array}{l}\text { Residents reporting it was somewhat or highly likely } \\
\text { they would practise in the following organizational models }\end{array}$} \\
\hline $\begin{array}{l}\text { Comprehensive care delivered in } 1 \text { clinical setting (e.g., office } \\
\text { based) (Q16a, } n=1659)\end{array}$ & $1019(61.4)$ & $320(57.5)$ & $416(63.7)$ & $32(47.8)$ & $251(65.7)$ & 0.004 \\
\hline $\begin{array}{l}\text { Comprehensive care provided across multiple clinical settings } \\
\text { (in-hospital, long-term care, office) (Q16b, 1661) }\end{array}$ & $1261(75.9)$ & $437(78.0)$ & $504(77.2)$ & $56(83.6)$ & $264(69.3)$ & 0.004 \\
\hline $\begin{array}{l}\text { Comprehensive care that includes a special interest (sports } \\
\text { medicine, emergency medicine, palliative care, etc.) } \\
\text { (Q16c, } n=1661 \text { ) }\end{array}$ & $1122(67.6)$ & $372(66.6)$ & $451(69.1)$ & $49(73.1)$ & $250(65.5)$ & 0.4 \\
\hline $\begin{array}{l}\text { Practice focused only on specific clinical areas (e.g., sports } \\
\text { medicine, maternity care, emergency medicine, palliative care, } \\
\text { hospital medicine) (Q16d, } n=1658 \text { ) }\end{array}$ & $522(31.5)$ & $225(40.3)$ & $179(27.5)$ & $18(26.9)$ & $100(26.3)$ & $<0.001$ \\
\hline Solo practice (Q15a, $n=1645)$ & $126(7.7)$ & $25(4.6)$ & $59(9.1)$ & $8(12.1)$ & $34(9.0)$ & 0.007 \\
\hline Group physician practice (Q15b, $n=1658$ ) & $1556(93.8)$ & $536(96.2)$ & $615(94.0)$ & $60(90.9)$ & $345(90.6)$ & 0.003 \\
\hline Interprofessional team-based practice (Q15c, $n=1656)$ & $1459(88.1)$ & $520(93.7)$ & $561(85.9)$ & $59(89.4)$ & $319(83.5)$ & $<0.001$ \\
\hline $\begin{array}{l}\text { Practice that includes teaching health profession learners } \\
\text { (Q15d, } n=1652)\end{array}$ & $1293(78.3)$ & $370(66.9)$ & $566(86.8)$ & $53(79.1)$ & $304(80.0)$ & $<0.001$ \\
\hline \multicolumn{7}{|c|}{$\begin{array}{l}\text { Residents reporting it was somewhat or highly likely they would } \\
\text { provide care in the following clinical domains in their first } 3 \text { years of practice }\end{array}$} \\
\hline Care across the life cycle (Q21a, $n=1658)$ & $1506(90.8)$ & $515(92.1)$ & $594(91.0)$ & $56(83.6)$ & $341(90.0)$ & 0.1 \\
\hline Intrapartum care (Q21b, $n=1654)$ & $623(37.7)$ & $174(31.2)$ & $276(42.5)$ & $28(41.8)$ & $145(38.3)$ & 0.001 \\
\hline Mental health care (Q21c, $n=1654)$ & $1467(88.7)$ & $484(86.7)$ & $587(90.3)$ & $60(89.6)$ & $336(88.7)$ & 0.3 \\
\hline Chronic disease management (Q21d, $n=1650$ ) & $1541(93.4)$ & $513(92.1)$ & $618(94.8)$ & $59(90.8)$ & $351(93.4)$ & 0.2 \\
\hline Palliative care, end-of-life care (Q21e, $n=1653$ ) & $1060(64.1)$ & $276(49.6)$ & $483(74.1)$ & $48(72.7)$ & $253(66.8)$ & $<0.001$ \\
\hline Office-based clinical procedures (Q21f, $n=1649$ ) & $1382(83.8)$ & $435(78.4)$ & $585(90.0)$ & $52(78.8)$ & $310(82.0)$ & $<0.001$ \\
\hline $\begin{array}{l}\text { In-hospital clinical procedures (e.g., chest tube insertion, } \\
\text { adult lumbar puncture, nasogastric tube insertion) } \\
\text { (Q21g, } n=1655)\end{array}$ & $646(39.0)$ & $193(34.6)$ & $296(45.5)$ & $24(35.8)$ & $133(35.1)$ & $<0.001$ \\
\hline \multicolumn{7}{|c|}{$\begin{array}{l}\text { Residents reporting it was somewhat or highly likely they would provide care } \\
\text { in the following practice settings or to the following populations in their first } 3 \text { years of practice }\end{array}$} \\
\hline In emergency departments (Q21h, $n=1656$ ) & $693(41.8)$ & $194(34.8)$ & $324(49.7)$ & $32(47.8)$ & $143(37.7)$ & $<0.001$ \\
\hline In hospital (Q21i, $n=1653$ ) & $983(59.5)$ & $315(56.7)$ & $430(66.0)$ & $49(74.2)$ & $189(49.9)$ & $<0.001$ \\
\hline In the home (Q21j, $n=1654)$ & $695(42.0)$ & $176(31.6)$ & $298(45.8)$ & $35(52.2)$ & $186(49.1)$ & $<0.001$ \\
\hline In long-term care facilities (Q21k, $n=1655$ ) & $678(41.0)$ & $169(30.3)$ & $344(52.8)$ & $27(40.3)$ & $138(36.4)$ & $<0.001$ \\
\hline $\begin{array}{l}\text { Marginalized, disadvantaged and vulnerable populations } \\
\text { (Q21I, } n=1652)\end{array}$ & $873(52.8)$ & $177(31.9)$ & $449(69.0)$ & $43(64.2)$ & $204(53.8)$ & $<0.001$ \\
\hline Rural populations (Q21m, $n=1577$ ) & $852(54.0)$ & $252(45.2)$ & $383(58.7)$ & $46(68.7)$ & $171(57.2)$ & $<0.001$ \\
\hline Elderly populations (Q21n, $n=1576$ ) & $1425(90.4)$ & $480(86.0)$ & $607(93.0)$ & $62(92.5)$ & $276(92.6)$ & $<0.001$ \\
\hline First Nations, Inuit and Métis (Q21o, $n=1656$ ) & $694(41.9)$ & $121(21.7)$ & $422(64.6)$ & $22(32.8)$ & $129(34.0)$ & $<0.001$ \\
\hline
\end{tabular}


Two-thirds of respondents $(67.6 \%, n=1122)$ indicated that they intended to have a comprehensive practice that included a special interest (Table 2), with no significant variation among regions (Appendix 2). Almost a third of respondents $(31.5 \%, n=522)$ indicated it was somewhat or highly likely that they would plan to focus only on specific clinical areas (Table 2). The odds of focused practice were highest in Ontario (Appendix 2).

Few respondents $(7.7 \%)$ indicated it was somewhat or highly likely they would work in a solo practice, while $93.8 \%$ and $88.1 \%$ of respondents reported they were somewhat or highly likely to work in a group physician practice and with interprofessional teams, respectively (Table 2). Relative to respondents from Ontario, respondents from the other regions had higher odds of intending to work in a solo practice and lower odds of intending to work in a group physician practice or interprofessional team (Appendix 2). Intentions to have a practice that included teaching health professional learners were lowest in Ontario $(66.9 \%, n=370)$ and highest in Western Canada $(86.8 \%, n=566)$ (Table 2). In multivariable analysis, relative to respondents from Ontario, respondents from all other regions had significantly higher odds of intending to pursue a practice that included teaching (Appendix 2).

\section{Clinical domains of practice}

We did not detect significant variation in intentions to provide care across the life cycle or to provide mental health care or chronic disease management (Table 2). Respondents from Ontario were less likely to report intentions to provide intrapartum and palliative care. Residents from Western Canada were more likely to report intentions to provide office-based clinical procedures.

\section{Practice settings and populations}

With respect to practice settings, nationally $42.0 \%(n=695)$ of respondents reported that they intended to provide care in the home and $41.0 \%(n=678)$ indicated that they intended to provide care in long-term care facilities. In Ontario these percentages were only $31.6 \%(n=176)$ and $30.3 \%(n=169)$, respectively (Table 2). Just over half $(52.8 \%, n=852)$ of physicians intended to provide care to marginalized, disadvantaged and vulnerable populations, and $41.9 \%(n=694)$ intended to provide care to First Nations, Inuit and Métis peoples. The odds of intending to have a practice serving marginalized populations and First Nations, Inuit and Métis peoples were lowest for Ontario respondents and highest for respondents from Western Canada (Appendix 2).

\section{Sensitivity analysis}

Sensitivity analyses confirmed that our results did not change given different analytic choices. Grouping "neutral" responses with "somewhat unlikely" and "highly unlikely" responses versus "somewhat likely" and "highly likely" responses, including the number of years since the respondent obtained their medical degree instead of the respondent's age, and excluding intentions for rural practice resulted in only very small changes in parameter estimates for regions.

\section{Interpretation}

Intentions to provide comprehensive care differed markedly across regions and did not appear to correspond to family medicine residents' confidence in their clinical ability (Table 2). These differences persisted when we adjusted for demographic variables and intentions for rural practice (Appendix 2). Almost a third of respondents $(31.5 \%, n=522)$ indicated that they were somewhat or highly likely to have a practice focused only on specific clinical areas. Over $80 \%$ of respondents across all regions expressed the intention to provide interprofessional, team-based care.

Differences in practice intentions among regions may reflect differences in the organization of primary care. For instance, in Ontario most family physicians work in a model of group physician or interdisciplinary team-based practice, ${ }^{24}$ whereas in Quebec, Atlantic Canada and Western Canada, supports for interdisciplinary practice are developing but have been more limited in scope.$^{8-10}$ Ontario family medicine residents were most likely to report that they intended to provide comprehensive care to the same group of patients for their first 3 years of practice, but they were the least likely to report that they intended to provide the full range of services. Team-based models may mean individual physicians can pursue focused practice while still contributing to comprehensive care for patients. In contrast, in Atlantic Canada, a higher proportion of respondents intended to provide care across multiple clinical settings and to rural populations.

Our results offer preliminary insight for policy and workforce planning. The finding that one-third of family medicine residents did not anticipate providing comprehensive primary care when they entered practice (Table 2) suggests workforce planning approaches that do not account for scope may overestimate the supply of individual physicians delivering comprehensive care. ${ }^{5}$ Models of primary care that integrate focused practice within a team whose members together deliver comprehensive services should be considered..$^{25}$ Approximately half of family medicine residents in our study indicated that they intended to provide care to marginalized, disadvantaged, vulnerable or Indigenous populations. As with other intentions to practice, this intention is probably influenced by the residents' values and/or training experience and may signal gaps in terms of who is recruited into medicine and the training contexts that these residents choose or are placed in. That over $80 \%$ of family medicine residents expressed intentions to provide interdisciplinary team-based care in all regions probably reflects the fact that team-based care is a focus of medical training at all Canadian medical schools; ${ }^{26}$ however, opportunities for team-based practice may not match this demand. ${ }^{10}$ Policy-makers and workforce planners should consider the impact of family medicine residents' intentions on policy objectives.

\section{Limitations}

Although response rates to this survey were high compared with those to other physician surveys ${ }^{27,28}$ and the demographic 
characteristics of the respondents appeared to be similar to those of residents in the Canadian Post-MD Education Registry, it is plausible that respondents and nonrespondents differed with respect to practice intentions. It is also possible that the perceived desirability of comprehensive family practice may have biased respondents and led to overreporting of intentions for comprehensive practice. In addition, the survey questions were not validated and no definitions of terms like comprehensive care were provided in the survey, and respondents may have interpreted terms differently across regions. For example, some respondents may have interpreted "comprehensive care in 1 clinical setting" as including locums or walk-in style practice. Furthermore, categorization of the Likert responses for analysis resulted in loss of information. We also had no information on respondents' province or medical school and so could not examine policy environments specific to each province nor adjust for characteristics unique to each training program in the models. We could observe only location of training, not region of subsequent practice, and so we could not observe practice intentions among family medicine residents likely to practise in the territories or in provinces other than where they trained. We have no information about how payment models shape practice intentions from this survey, but there is evidence that payment models may shape practice choice ${ }^{11-14}$ and evidence that early-career primary care physicians may prefer non-fee-for-service models of compensation. ${ }^{29}$ The impacts of misalignment between aspirational practice intentions of graduating family physicians and actual opportunities for team-based practice are not known. Finally, it is unknown whether our study's findings are unique to the current cohort of family medicine residents or whether they reflect changing practice intentions, and potentially changes in actual practice, among physicians of all ages. We performed multiple comparisons to explore family medicine residents' intentions to practice and as such our study should be considered preliminary and descriptive. Although some significant findings could be spurious, large differences in practice intentions signal areas for further exploration by health policy researchers and health human resources planners.

\section{Conclusion}

If intentions to focus only on specific clinical areas translate into practice, changes to the organization of primary care that integrate focused practice within comprehensive teams and/or changes to workforce planning may be needed to ensure access to comprehensive care. The findings that most family medicine residents intend to practise in group physician or interdisciplinary team-based organizational models could prompt consideration of whether practice opportunities are in line with these expectations across all regions. Further research is needed to determine whether practice intentions correspond to actual practice and to better understand what additional factors shape the choices family physicians make as they navigate the early stages of their careers.

\section{References}

1. Physicians in Canada, 2016: summary report. Ottawa: Canadian Institute for Health Information; 2017:1-27. Available: https://www.cihi.ca/sites/default/ files/document/physicians_in_canada_phys2016_en.pdf (accessed 2018 June 18).

2. CANSIM Table 105-0501-Health indicator profile, annual estimates by age group and sex, Canada, provinces, territories, bealth regions (2013 boundaries) and peer groups. 2008-2011. Ottawa: Statistics Canada. Available: http://www5.statcan. gc.ca/cansim/a26?lang=eng\&id=1050501 (accessed 2016 Jan. 13).

3. How Canada compares: results from The Commonwealth Fund 2015 International Health Policy Survey of Primary Care Physicians. Ottawa: Canadian Institute for Health Information; 2016. Available: https://www.cihi.ca/sites/default/files/ document/commonwealth_fund_2015_pdf_en.pdf (accessed 2018 Oct. 9).

4. How Canada compares: results from The Commonwealth Fund's 2016 International Health Policy Survey of Adults in 11 Countries. Ottawa: Canadian Institute for Health Information; 2017. Available: https://www.cihi.ca/en/health-system -performance/performance-reporting/international/wait-times-for-primary-and -specialist. (accessed 2018 Oct. 9).

5. Hedden L, Barer ML, McGrail K, et al. In British Columbia, the supply of primary care physicians grew, but their rate of clinical activity declined. Health Aff (Millwood) 2017;36:1904-11.

6. Chan BTB. The declining comprehensiveness of primary care. CMAJ 2002;166:429-34.

7. Lavergne MR, Peterson S, McKendry R, et al. Full-service family practice in British Columbia: policy interventions and trends in practice, 1991-2010. Healthc Policy 2014;9:32-47.

8. Strumpf E, Levesque J-F, Coyle N, et al. Innovative and diverse strategies toward primary health care reform: lessons learned from the Canadian experience. 7 Am Board Fam Med 2012;25(Suppl 1):S27-33.

9. Aggarwal M, Hutchison B. Toward a primary care strategy for Canada. Ottawa: Canadian Foundation for Healthcare Improvement; 2012. Available: https://www .google.ca/url? $\mathrm{sa}=\mathrm{t} \& \mathrm{rct}=\mathrm{j} \& \mathrm{q}=\&$ esrc $=\mathrm{s} \&$ source $=$ web $\& \mathrm{~cd}=5 \& \mathrm{cad}=\mathrm{rja} \& u a c t=8 \&$ ved =0ahUKEwip4ZzX-4fMAhWLHR4KHRGtB0IQFggzMAQ\&url=http://www. cfhi-fcass.ca/Libraries/Reports/Primary-Care-Strategy-EN.sflb.ashx\&usg=AFQj CNGuSzzp0NwAyQetXPeVddE2OffjoA (accessed 2018 Nov. 13).

10. Peckham A, Ho J, Marchildon G. Policy innovations in primary care across Canada: a rapid review prepared for the Canadian Foundation for Health Innovation. Toronto: North American Observatory on Health Systems and Policies; 2018.

11. McGuire TG. Physician agency and payment for primary medical care. Oxford Handb Heal Econ 2011;602-23.

12. Leger P. Physician payment mechanisms. In: Financing health care. Weinheim, (Germany): Wiley-VCH Verlag GmbH \& Co. KGaA; 2007:149-76.

13. Gosden T, Forland F, Kristiansen IS, et al. Capitation, salary, fee-for-service and mixed systems of paymen: effects on the behaviour of primary care physicians. Cochrane Database Syst Rev 2011;(3):CD002215.

14. Gosden T, Forland F, Kristiansen I. Impact of payment method on behaviour of primary care physicians: a systematic review. 7 Health Serv Res Policy 2001;6:44-55.

15. Kiolbassa K, Miksch A, Hermann K, et al. Becoming a general practitioner Which factors have most impact on career choice of medical students? BMC Fam Pract 2011;12:25.

16. Connelly MT, Sullivan AM, Peters AS, et al. Variation in predictors of primary care career choice by year and stage of training. F Gen Intern Med 2003;18:159-69.

17. Scott I, Wright B, Brenneis F, et al. Why would I choose a career in family medicine? Reflections of medical students at 3 universities. Can Fam Physician 2007;53:1956-7.

18. Bennett KL, Phillips JP. Finding, recruiting, and sustaining the future primary care physician workforce: a new theoretical model of specialty choice process. Acad Med 2010;85:S81-8.

19. Oandasan IF, Archibald D, Authier L, et al. Future practice of comprehensive care: Practice intentions of exiting family medicine residents in Canada. Can Fam Physician 2018;64:520-8.

20. Grierson LEM, Fowler N, Kwan MYW. Family medicine residents' practice intentions: theory of planned behavior evaluation. Can Fam Physician 2015;61:e524-31.

21. Oandasan I, Saucier D, editors. A national program evaluation approach to study the impact of Triple C. In: Triple C competency-based curriculum report - part 2: advancing implementation. Mississauga (ON): College of Family Physicians of Canada; 2013. Available: www.cfpc.ca/uploadedFiles/Education/_PDFs/TripleC _Report_pt2.pdf (accessed 2018 Nov. 14).

22. Family Medicine Longitudinal Survey: T2 (exit) results 2016. Aggregate data for 16 participating programs. Family medicine residency programs. Mississauga (ON): College of Family Physicians of Canada; 2016.

23. Walton M, Rourke J, Bowmer I, et al. 2016-2017 Annual census of post-M.D. trainees. Ottawa: CAPER[Canadian Post-M.D. Education Registry]-RCEP; 2017. Available: https://caper.ca/ assets/documents/2016-17_CAPER_ Census_en.pdf (accessed 2018 July 4).

24. Hutchison B, Glazier R. Ontario's primary care reforms have transformed the local care landscape, but a plan is needed for ongoing improvement. Health Aff (Millwood) 2013;32:695-703.

25. Contandriopoulos D, Perroux M, Cockenpot A, et al. Analytical typology of multiprofessional primary care models. BMC Fam Pract 2018;19:44.

26. A collective vision for postgraduate medical education in Canada. Ottawa: The Association of Faculties of Medicine of Canada; 2012. 
27. Cunningham CT, Cai P, Topps D, et al. Mining rich health data from Canadian physician claims: features and face validity. BMC Res Notes 2014;7:682

28. Kellerman SE, Herold J. Physician response to surveys: a review of the literature. Am 7 Prev Med 2001;20:61-7.

29. Brcic V, McGregor M, Kaczorowski J. Practice and payment preferences of newly practising family physicians in British Columbia. Can Fam Physician 2012;58:275-81.

Affiliations: Faculty of Health Sciences (Lavergne, Goldsmith, Hedden), Simon Fraser University, Burnaby, BC; Department of Family Practice (Scott, Mitra), Faculty of Medicine, University of British Columbia, Vancouver, BC; Department of Family Practice (Snadden), Faculty of Medicine, University of British Columbia Northern Medical Program, Prince George, BC; School of Leadership Studies (Blackie), Royal Roads University, Victoria, BC; University of Ontario Institute of Technology (Rudoler), Oshawa, Ont.; Telfer School of Management (Grudniewicz), University of Ottawa, Ottawa, Ont.; Centre for Health Services and Policy Research (Ahuja), School of Population and Public Health, University of British Columbia, Vancouver, BC; Department of Family Medicine (Marshall), Faculty of Medicine, Dalhousie University, Halifax, NS
Contributors: Ruth Lavergne completed the statistical analysis and led the drafting of the manuscript. All other authors contributed to the study design and revised the manuscript for important intellectual content. All authors gave final approval of the version to be published and agreed to act as guarantors of the work.

Funding: This study was supported by the Canadian Institutes of Health Research (project grant no. 155965).

Acknowledgements: The authors would like to acknowledge the College of Family Physicians of Canada and the 17 university-based family medicine residency programs who have partnered to evaluate the Triple $\mathrm{C}$ competency-based curriculum, which provided the survey data used in this publication. The views and opinions expressed in this paper do not necessarily reflect the views of the College of Family Physicians of Canada or the universities.

Supplemental information: For reviewer comments and the original submission of this manuscript, please see www.cmajopen.ca/content/7/1/ E124/suppl/DC1. 